\title{
Joint Occurrence of Daily Temperature and Precipitation Extreme Events over Canada*
}

\author{
BÁrbara TENCER AND ANDREW WeAVER \\ School of Earth and Ocean Sciences, University of Victoria, Victoria, British Columbia, Canada \\ FRANCIS ZWIERS \\ Pacific Climate Impacts Consortium, University of Victoria, Victoria, British Columbia, Canada
}

(Manuscript received 26 November 2013, in final form 21 May 2014)

\begin{abstract}
The occurrence of individual extremes such as temperature and precipitation extremes can have a great impact on the environment. Agriculture, energy demands, and human health, among other activities, can be affected by extremely high or low temperatures and by extremely dry or wet conditions. The simultaneous or proximate occurrence of both types of extremes could lead to even more profound consequences, however. For example, a dry period can have more negative consequences on agriculture if it is concomitant with or followed by a period of extremely high temperatures. This study analyzes the joint occurrence of very wet conditions and high/low temperature events at stations in Canada. More than one-half of the stations showed a significant positive relationship at the daily time scale between warm nights (daily minimum temperature greater than the 90th percentile) or warm days (daily maximum temperature above the 90th percentile) and heavy-precipitation events (daily precipitation exceeding the 75th percentile), with the greater frequencies found for the east and southwest coasts during autumn and winter. Cold days (daily maximum temperature below the 10th percentile) occur together with intense precipitation more frequently during spring and summer. Simulations by regional climate models show good agreement with observations in the seasonal and spatial variability of the joint distribution, especially when an ensemble of simulations was used.
\end{abstract}

\section{Introduction}

Temperature and precipitation extreme events have been separately studied around the globe because their occurrence severely impacts built and natural systems (McGregor et al. 2005). Agriculture, energy demands, and human health, among other activities, can be affected by extremely high or low temperatures and by extremely dry or wet conditions.

Heat waves and their impacts have also been a subject of study for many years. A few examples include the

\footnotetext{
* Supplemental information related to this paper is available at the Journals Online website: http://dx.doi.org/10.1175/JAMC-D13-0361.s1.

Corresponding author address: Bárbara Tencer, School of Earth and Ocean Sciences, University of Victoria, P.O. Box 1700, Station CSC, Victoria, BC V8W2Y2, Canada.

E-mail: btencer@uvic.ca
}

heat wave that affected Europe in the summer of 2003, which led to extensive drought, crop losses of around $\$ 12.3$ billion, increases in electricity prices, rockfalls in the Alps caused by thawing of permafrost, and more than 22000 heat-related deaths (Schär and Jendritzky 2004; Levinson and Waple 2004). A heat wave lasting from July to early September of 2003 in southern China caused heat-related deaths, record-breaking electricity consumption, and great losses of rice, cotton, and corn (Ding and Qian 2011). In 2008, the city of Shanghai, China, suffered an increase of $13 \%$ in daily mortality as a result of an 8-day cold spell (Ma et al. 2013), and Kysely et al. (2009) observed significant effects of cold spells on cardiovascular mortality, with excess mortality ranging from $14 \%$ to $30 \%$ for various cold-spell periods in the Czech Republic. In 2010, an intense heat wave affected Russia and resulted in more than 15000 deaths and an economical loss of more than $\$ 15$ billion (Lau and Kim 2012). Because of very dry precedent conditions, more than 600 wildfires occurred in the region, 
leading to an increase in smog levels of up to 5-8 times normal levels (Matsueda 2011). According to Trenberth and Fasullo (2012), this was not an isolated event: extremely high sea surface temperatures in several places around the world during 2010 provided a source of above-normal atmospheric moisture in monsoonal regions, leading to flooding in Pakistan, Colombia, and Queensland in Australia; the anomalous diabatic heating released altered the monsoonal circulation as well as the circulation at higher latitudes, allowing the persistent anticyclonic circulation associated with the extreme temperatures observed in Russia.

Over Canada, extreme-cold events during winter can lead to health and safety hazards and great disturbances in economic activities (Shabbar and Bonsal 2003). Although less studied, heat waves also represent a natural hazard for Canada. For example, extreme-temperature conditions were observed in Québec during July of 2010. With maximum temperatures above $30^{\circ} \mathrm{C}$, minimum temperatures over $20^{\circ} \mathrm{C}$, and high humidity lasting 4-5 days, this unprecedented heat wave led to a significant increase of $33 \%$ in the death rate and $4 \%$ in the admission rate to emergency departments in comparison with the previous five years (Bustinza et al. 2013).

Significant changes in temperature extremes consistent with warming have been observed throughout the world during the past century, with stronger trends during more recent decades. Precipitation extremes also show upward trends in the global mean, with more areas of significant increasing trends in the amount, intensity, and frequency of occurrence of heavy precipitation than areas with decreasing trends (Donat et al. 2013; Westra et al. 2013). Projections for a warmer climate indicate that extremeprecipitation events will very likely become more intense and frequent by the end of the century over most of the midlatitude landmasses (Stocker et al. 2013), pushing toward a higher risk of flooding (Trenberth 1999). Floods are one of the most extensive and significant natural hazards on Earth, both in terms of economics and social impacts. River and coastal floods affect on average 520 million people per year, with the annual cost to the world economy exceeding $\$ 60$ billion (Simonovic 2009). In Canada, floods led to at least 200 deaths during the twentieth century and over \$2 billion in damage (Jakob and Church 2011). The recent flood that affected Calgary, Alberta, in Canada in 2013 is estimated to have cost more than 6 billion Canadian dollars in damage losses and recovery costs according to a report by Environment Canada (http://ec.gc.ca/meteo-weather/default.asp? lang $=$ En\&n $=5$ BA5EAFC-\&offset $=2 \&$ toc $=$ show ).

Simple extremes as described above are characterized by a single variable such as temperature or precipitation, which are two of the most important variables that describe our climate. Complex extremes involving the simultaneous or proximate occurrence of different types of extremes could lead to more profound consequences, however. For example, a dry period can have more negative consequences on agriculture if it is concomitant with or followed by a period of extremely high temperatures (Jiang and Huang 2000).

The relationship between temperature and precipitation has been studied mostly in terms of mean values. Madden and Williams (1978) computed correlations between seasonal mean temperature and precipitation totals in the United States and Europe and found that cool summers tend to be wet while droughts are more frequently associated with heat waves. On a global scale, Trenberth and Shea (2005) found a strong negative correlation between monthly mean surface temperature and precipitation over continental land in summer in both hemispheres, indicating that summers tend to be either hot and dry or cool and wet. During winter, this relationship is reversed over land at high latitudes, reflecting the increased moisture-holding capacity of air with temperature and the role of the warm, moist advection process in extratropical storms. According to Isaac and Stuart (1992), who analyzed the precipitationtemperature relationship at Canadian stations using daily data, the majority of winter precipitation falls when temperatures are higher than the median, with the exception of the Rocky Mountains region and the plains to the east, while during summer wet conditions are generally associated with cooler days.

The purpose of this study is to explore the relationship between heavy precipitation and extreme-temperature events in Canada by analyzing the joint occurrence of very wet conditions and extremely high or low temperatures using daily data observed during the twentieth century. The existence of a significant statistical relation between these extremes could help to better characterize the uncertainties associated with projections of extreme-precipitation events for a future warmer climate. Therefore, in this study North American Regional Climate Change Assessment Program (NARCCAP; Mearns et al. 2012) model runs are also examined to verify whether regional climate models are able to simulate the relationship between heavy precipitation and extreme-temperature events depicted by station data.

The remainder of this paper is organized as follows. Section 2 describes the data and method used in this study in more detail. A description of the observational results is given in section 3, followed by an assessment of the model performance. Section 4 provides an overall summary and the main conclusions found in this study. 


\section{Data and method}

\section{a. Observed data}

Daily precipitation, minimum temperature, and maximum temperature ( $\mathrm{Pr}, \mathrm{Tn}$, and Tx, respectively) from 293 stations across Canada from the Adjusted and Homogenized Canadian Climate Data (AHCCD; Mekis and Vincent 2011; Vincent et al. 2012) were used in this study (Fig. 1). This dataset provides daily data for different periods, depending on the station, with the majority of the records starting before 1950 and extending until 2011. Daily total precipitation was calculated by adding the stations' adjusted daily rainfall and snow water equivalent. Rain gauge values reported in the AHCCD are adjusted values that account for wind undercatch, evaporation, and wetting losses, and density corrections were applied to all ruler measurements of snowfall on the basis of coincident ruler and Nipher gauge observations. Both measurements were adjusted for trace observations and accumulated amounts from several days. Also, records from neighboring stations were joined by employing a technique that is based on a simple ratio of observations to produce longer time series (Mekis and Vincent 2011). Daily minimum and maximum temperature series were adjusted to account for changes in the observing time and other nonclimatic inhomogeneities using a quantilematching algorithm (Vincent et al. 2012).

\section{b. Model output simulations}

Daily series of precipitation and temperature simulated by regional climate models (RCMs) from NARCCAP (Mearns et al. 2012; data were obtained online in 2012 from the NARCCAP dataset at the National Center for Atmospheric Research Earth System Grid data portal at doi:10.5065/D6RN35ST) for past climate were also used in this study. Three different RCMs were considered: ${ }^{1}$ the Met Office Hadley Centre's regional climate model, version 3 (HRM3; Jones et al. 2003); the Regional Climate Model, version 3 (RCM3; Giorgi et al. 1993a,b; Pal et al. 2000, 2007); and the Weather Research and Forecasting (hereinafter WRFG) Model (Skamarock et al. 2005). Each RCM simulation was run using boundary conditions from the National Centers for Environmental Prediction-U.S. Department of Energy R-2 reanalysis (hereinafter NCEP; Kanamitsu et al. 2002) for the period 1980-2004 and from two different GCMs for the period 1971-2000: the Geophysical Fluid Dynamics Laboratory

\footnotetext{
${ }^{1}$ Only three RCMs were used in this study because of the lack of availability of daily precipitation and temperature data for the rest of the models involved in the project at the time that this research was started.
}

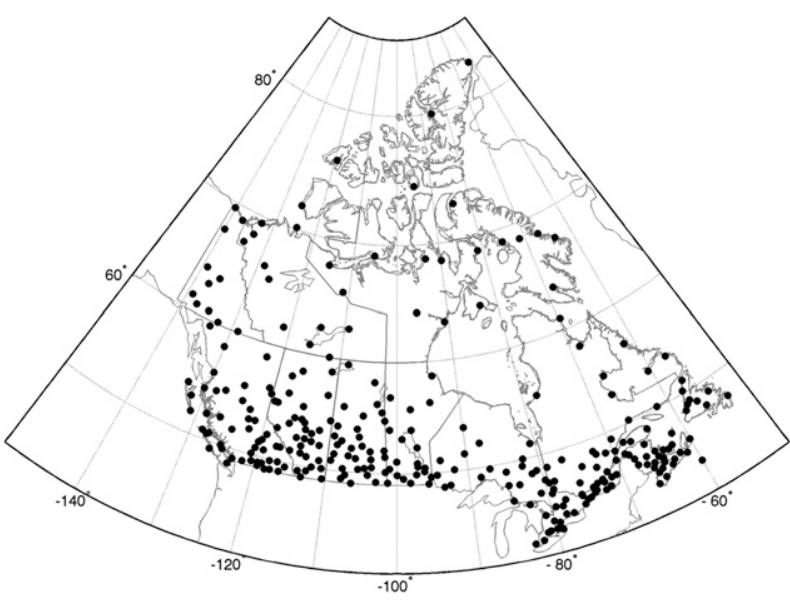

FIG. 1. Stations used in this study: 293 stations with daily precipitation, minimum temperature, and maximum temperature.

Climate Model, version 2.1 (GFDL CM2.1; GFDL Global Atmospheric Model Development Team 2004), and the Hadley Centre Coupled Model, version 3 (HadCM3; Gordon et al. 2000; Pope et al. 2000), for HRM3; the Canadian Centre for Climate Modelling and Analysis Third Generation Coupled General Climate Model (CGCM3; Scinocca and McFarlane 2004; Flato et al. 2000, and see online at http://www.ec.gc.ca/ccmaccccma/default.asp? $n=1299529 \mathrm{~F}-1$ ) and the GFDL CM2.1 for RCM3; and the National Center for Atmospheric Research Community Climate System Model, version 3 (CCSM; Collins et al. 2006), and CGCM3 for the WRFG.

\section{c. Individual extreme-event definition}

From daily data, heavy-precipitation events were defined as those days on which the daily accumulated precipitation exceeded a predefined threshold. This threshold was chosen to be the daily 75 th percentile of the distribution of rainy days $(\operatorname{Pr}>0.1 \mathrm{~mm})$, calculated empirically from the sample of all rainy days in a base period, over a 29-day-running window centered on each calendar day. Because the observed rainfall probability across Canada is on average 0.5 , exceedance of the 75 th percentile of the distribution of rainy days represents the upper tail of the distribution of all days, with annual probability of occurrence of approximately $12.5 \%$. This reference value may change from season to season and for individual stations because of changes in the rainfall probability but shows that heavy-precipitation events as defined in this study have a probability of occurrence that is much lower than $25 \%$.

For temperature, four different extremes were defined on the basis of minimum and maximum temperature separately. Warm days correspond to days with 
Tx exceeding the daily 90th percentile of its distribution, and cold days refer to days with Tx below the 10th percentile. Warm nights are recorded when Tn exceeds the 90th percentile of its own distribution, and cold nights are recorded when Tn is less than the 10th percentile. As with precipitation, thresholds for temperature extremes were computed as percentiles of the empirical distribution of daily minimum and maximum temperature for each calendar day. Because temperature is a smoother variable than precipitation, a 5-dayrunning window was used in this case, following the practice recommended by the joint World Meteorological Organization Commission for Climatology/ Climate Variability and Predictability/Joint Technical Commission for Oceanography and Marine Meteorology Expert Team on Climate Change Detection and Indices (Zhang et al. 2011).

Because percentiles are relative to local climate, the selection of this kind of threshold allows us to take into consideration different temperature and precipitation regimes across the country. As a result of seasonality in both variables, the use of daily thresholds enables events to be extreme relative to values that are normal for that particular season without the need to be extreme in absolute terms for the whole year. Out-of-season values (e.g., nonseasonal frost) can have a huge impact on the ecosystem because they imply a sudden and abrupt change, even though they might represent normal conditions at other times of the year.

Higher percentiles were also analyzed as thresholds to define individual extreme events. Results found for the occurrence of the compound extremes when more extreme individual events were considered are similar to those shown in section 3, although they are less significant and robust because of the low number of cases found in the period of study.

\section{d. Compound extreme-event definition}

Joint extreme events were defined as those days on which a heavy-precipitation event occurred together with one of the four different temperature extreme events. For each combination of precipitation and temperature extreme event, the frequencies of all possible events were organized into a contingency table with entries $n_{p t}$, where $p=1$ or 2 corresponds to extreme or nonextreme precipitation, respectively, and $t=1$ or 2 corresponds to extreme or nonextreme temperature, respectively. From these values, the percentage of days with both extremes over the total extreme-temperature events in the season was calculated as follows:

$$
x=100 \frac{n_{11}}{n_{11}+n_{21}},
$$

where $n_{11}$ corresponds to the number of days with both extremes and $n_{11}+n_{21}$ is the total number of days in the season showing an extreme-temperature event. In the absence of any dependence between the occurrence of precipitation and temperature extremes, $x$ is equal to the percentage of heavy-precipitation events expected for that season and location, which can be calculated as the exceedance rate $(25 \%$ as per the threshold used in this study) times the rainfall probability.

The joint occurrence of precipitation and temperature extreme events was also studied by applying a \pm 1 -day lag to the heavy-precipitation events, that is, cases of heavy precipitation occurring on the day before or after a temperature extreme event.

\section{e. Significance test}

The significance of this relationship was analyzed by applying a one-tail chi-square test (Wilks 2011) at the $5 \%$ significance level. The null hypothesis for this test is that the events are independent and therefore the occurrence of a heavy-precipitation event is not conditioned by the occurrence of a temperature extreme event, or vice versa. Under this hypothesis, the joint probability can be calculated as the product of the two individual event probabilities:

$$
e_{p t}=n_{p .} n_{. t} / n
$$

where $n_{p}$. is the total number of heavy-precipitation events, $n_{. t}$ is the total number of extreme-temperature events, and $n$ is the total number of the days in the period of study. The test statistic is computed on the basis of the observed and expected values as follows:

$$
\chi^{2}=\sum_{p=1}^{2} \sum_{t=1}^{2} \frac{\left(\left|n_{p t}-e_{p t}\right|-0.5\right)^{2}}{e_{p t}},
$$

taking into account Yates's correction for a $2 \times 2$ contingency table (Yates 1934, 1984), where the statistic $\chi^{2}$ follows a chi-square distribution with $\nu=1$ degree of freedom.

By applying a resampling procedure, the field significance of the relationship between heavy precipitation and extreme-temperature events was analyzed. The dependence between extremes was computed for the observed time series, as well as for 1000 resampled realizations. The resampling was performed using a moving-5-yrblocks bootstrap that accounts for autocorrelation (Wilks 1997), and the same resampling procedure (with replacement) was applied to all stations in the dataset to keep the spatial dependence between locations. For each realization, the frequency of occurrence of each joint extreme was computed and tested for significance. Two 
statistics were considered from each realization: the percentage of locations with a significant relationship and the mean frequency of occurrence of each joint extreme over all locations for each season. The 5th and 95th percentiles of the resulting collection of these two statistics estimates are then used as lower and upper $90 \%$ confidence limits for the observed values (see Tables 1 and 2 in section 3).

\section{Results}

\section{a. Observed joint distribution}

The analysis of the joint distribution of precipitation and temperature extreme events was performed at 293 stations across Canada. For the sake of comparison with RCM simulations, results for the observations are presented in Figs. 2-5 and Tables 1 and 2 for the period 1980-2004. Similar results were obtained when performing the analysis over the longest available period at each station, with almost all stations showing significant relationships between precipitation and temperature extreme events.

Figures $2 \mathrm{a}$ and $2 \mathrm{c}$ show the observed joint occurrence of warm nights and heavy-precipitation events for winter and summer, respectively (see Figs. S1a,c in the supplemental material for the shoulder seasons). Results are shown as a ratio over the expected value (see section $2 \mathrm{~d}$ for details on how the expected value was computed), with red colors indicating a positive relationship (i.e., higher frequency of joint extreme events than is expected under the assumption of independence) and blue colors denoting a negative relationship (i.e., less frequency than is expected). As can be seen, the relationship between warm nights and heavy precipitation is positive in almost all of Canada, except in Alberta and Saskatchewan where a negative relationship is observed during winter, although only significant at less than $10 \%$ of the stations. The positive signal is stronger during autumn and winter with one-half or more of the analyzed stations showing a significant relationship at the $5 \%$ level (see section $2 \mathrm{e}$ for details on the statistical test used). Over the whole country an average of $25.6 \%$ of the warm nights in winter also present a heavy-precipitation event on the same day (Table 1). This relationship is clearly stronger along the east and southwest coasts, however, where more than $40 \%$ of warm nights are coincident with heavyprecipitation events at some of the stations, which is possibly related to weather phenomena such as the "Pineapple Express" in the west (Geng et al. 2012). For all seasons, the occurrence of heavy-precipitation events shows a significant positive relationship with warm nights when averaged over all locations (Table 1), since

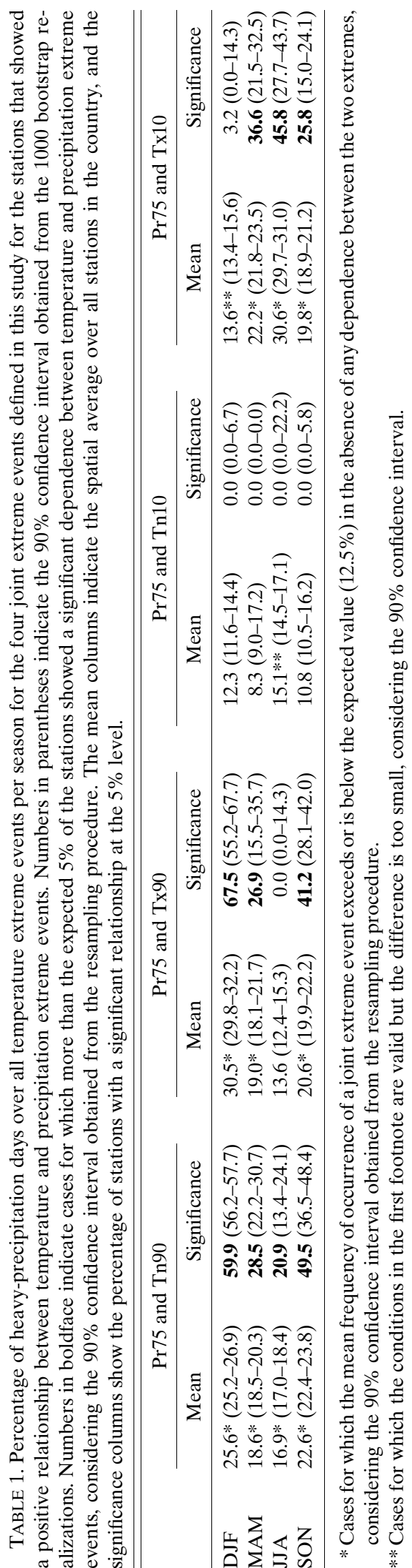


TABLE 2. As in Table 1, but for locations with a negative relationship.

\begin{tabular}{|c|c|c|c|c|c|c|c|c|}
\hline & \multicolumn{2}{|c|}{ Pr75 and Tn90 } & \multicolumn{2}{|c|}{ Pr75 and Tx90 } & \multicolumn{2}{|c|}{$\operatorname{Pr} 75$ and Tn10 } & \multicolumn{2}{|c|}{ Pr75 and Tx10 } \\
\hline & Mean & Significance & Mean & Significance & Mean & Significance & Mean & Significance \\
\hline DJF & $8.2 *(7.5-8.7)$ & $8.8(3.5-10.8)$ & $7.0 *(6.3-7.3)$ & $14.4(9.5-16.8)$ & $7.6 *(6.9-7.7)$ & $40.6(34.8-44.4)$ & $5.1 *(4.6-5.4)$ & $45.4(39.0-48.4)$ \\
\hline MAM & $9.5 *(8.3-9.8)$ & $1.0(0.0-3.0)$ & $5.4 *(5.0-5.7)$ & $22.8(14.8-22.9)$ & $5.1 *(4.4-5.2)$ & $31.0(21.3-29.7)$ & $7.2 *(6.5-8.1)$ & $12.1(8.5-15.8)$ \\
\hline JJA & $9.2 *(8.5-9.5)$ & $5.4(2.5-9.2)$ & $5.0 *(4.8-5.4)$ & $32.8(19.0-30.9)$ & $5.2 *(4.7-5.4)$ & $26.9(16.4-26.2)$ & $12.1(8.5-13.7)$ & $0.0(0.0-1.4)$ \\
\hline SON & $9.1 *(7.9-9.8)$ & $1.9(0.0-3.4)$ & $6.3 *(6.0-6.9)$ & $18.8(13.6-20.4)$ & $6.4 *(5.6-6.8)$ & $37.0(29.3-38.5)$ & $10.9 * *(9.6-11.0)$ & $12.7(11.3-23.1)$ \\
\hline
\end{tabular}

* Cases for which the mean frequency of occurrence of a joint extreme event exceeds or is below the expected value (12.5\%) in the absence of any dependence between the two extremes, considering the $90 \%$ confidence interval obtained from the resampling procedure.

** Cases for which the conditions in the first footnote are valid but the difference is too small, considering the $90 \%$ confidence interval.

the observed frequency is always greater than the expected $12.5 \%$ under the assumption of no dependence, even considering the $90 \%$ confidence interval given by the bootstrap procedure. Even more, the significance test described in the previous section implies that about $5 \%$ of the stations might show a significant relationship (either positive or negative) by random chance. The $90 \%$ confidence interval of the percentage of locations at which a significant positive relationship was observed obtained from the bootstrap procedure is considerably higher than the expected $5 \%$. This is not the case for the locations with a negative relationship (Table 2).

When combined with warm days, heavy-precipitation events also happen significantly more frequently along the east and southwest in winter and on the east coast and the north during autumn (Figs. $2 \mathrm{~b}$ and S1d). The a) Pr75 \& Tn90 - DJF

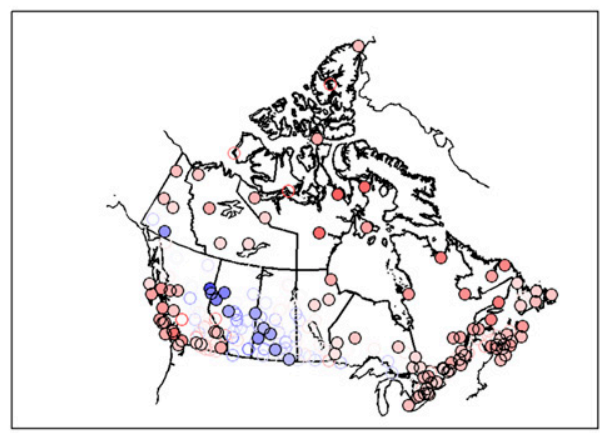

\section{b) Pr75 \& Tx90 - DJF}

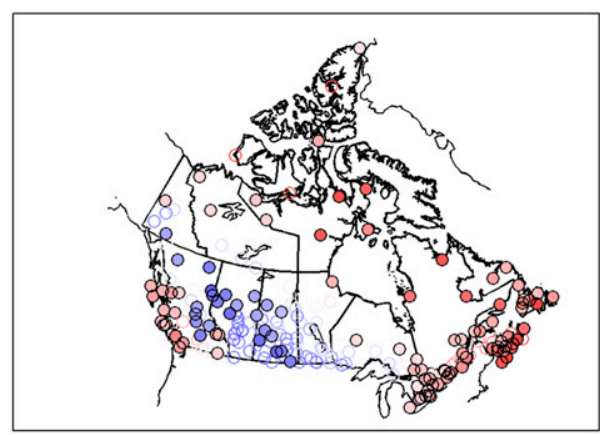

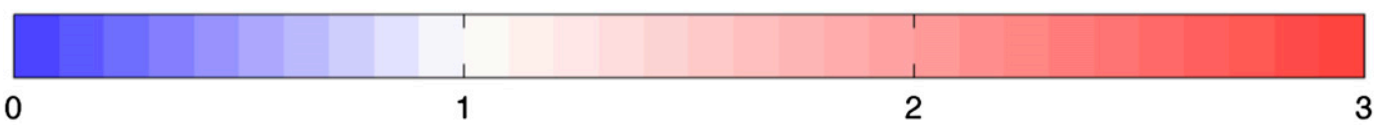

c) Pr75 \& Tn90 - JJA

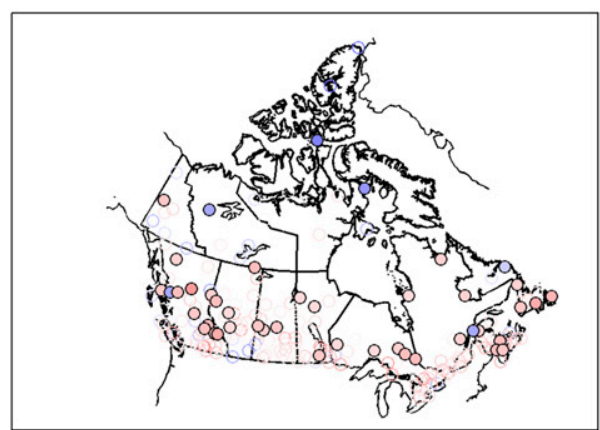

d) Pr75 \& Tx90 - JJA

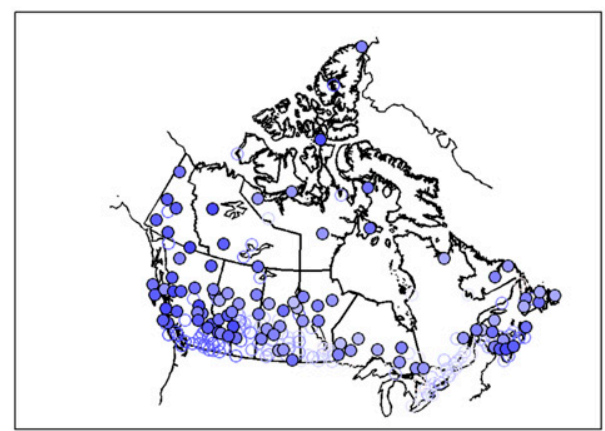

FIG. 2. Percentage of (left) warm nights and (right) warm days occurring simultaneously with heavy-precipitation events for (a),(b) winter and (c),(d) summer, expressed as a ratio over the expected value (see text for more detail). Filled symbols indicate a significant relationship at the $5 \%$ level. 
a) Pr75 \& Tn10 - DJF

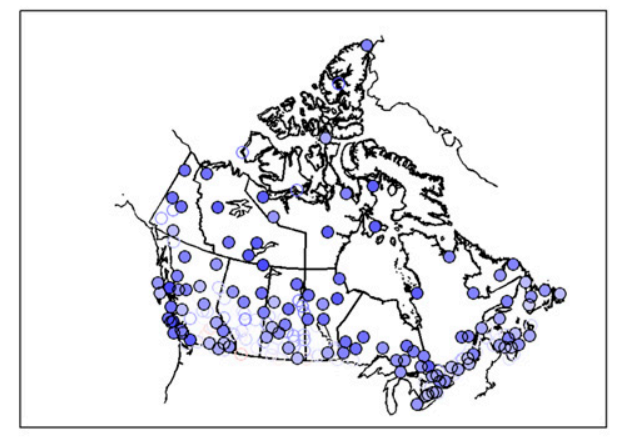

b) Pr75 \& Tx10 - DJF

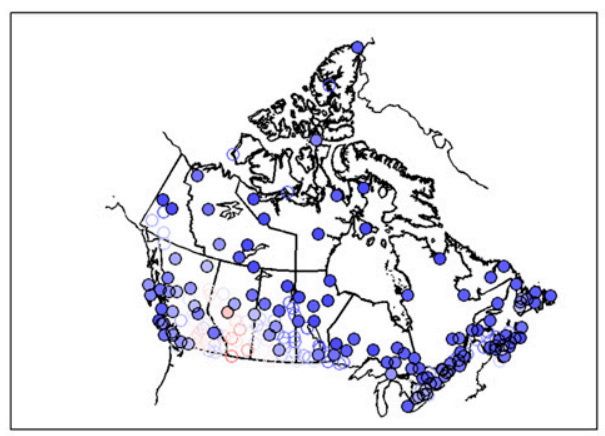

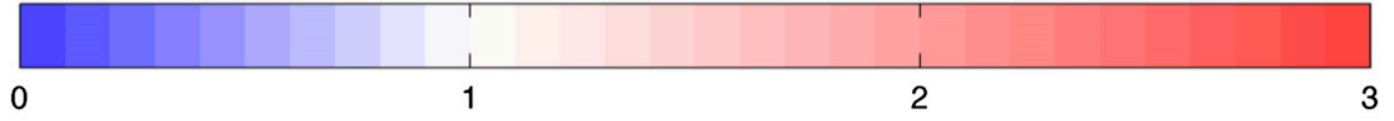

c) Pr75 \& Tn10 - JJA

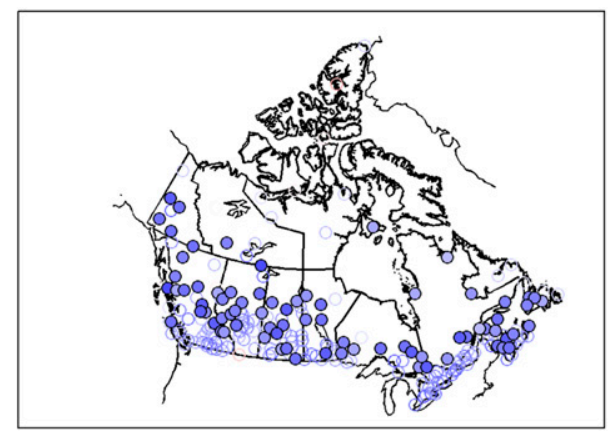

d) Pr75 \& Tx10 - JJA

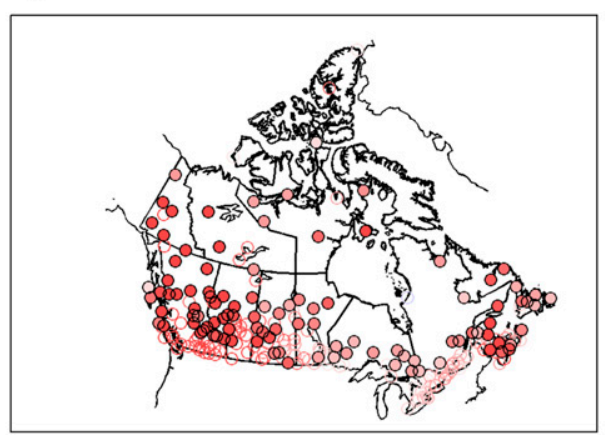

FIG. 3. As in Fig. 2, but for (a),(c) cold nights and (b),(d) cold days.

relationship is negative everywhere during summer, however, with an average of only $5 \%(4.8 \%-5.4 \%$, according to the $90 \%$ confidence interval; Table 1) of the warm days occurring together with heavy precipitation. During spring, the north shows a positive relationship at $26.9 \%$ of the stations, with an average frequency of $19.0 \%$ $(18.1-21.7 \%)$, while the south has heavy-precipitation events on $5.4 \%(5.0 \%-5.7 \%)$ of the warm days, significant at more than one-fifth of the stations.

The concurrent occurrence of heavy-precipitation events and cold days (Figs. 3b,d and Figs. S2b,d of the supplemental material) is somewhat opposite to the pattern seen for warm days. A negative relationship is observed at almost all stations during winter and is significant at one-half of them, with a spatial average of only $5.1 \%$ $(4.6 \%-5.4 \%)$ of occurrence of the joint extreme event. During summer, this pattern is reversed and almost onethird of the cold days in the season happen together with a heavy-precipitation event. The significance is lower during the shoulder seasons (Fig. S2), with positive significant relationships in the southern (southwestern) part of the country during spring (autumn) while the north (northeast) shows a negative relationship. In both cases the number of locations at which the relationship was significant is greater than the expected $5 \%$ by random chance (see Tables 1 and 2).

The relation between heavy-precipitation events and cold nights was negative over the whole country and throughout the year, significant at approximately onethird of the stations (Figs. 3a,c and S2a,c). This shows that heavy-precipitation events do not usually occur under nocturnal cold conditions at any time of the year.

The same analysis was performed while lagging the events by 1 day to address the question of whether one type of extreme event leads the other one. As was found for the simultaneous occurrence, heavy precipitation occurring on the day before a warm night tends to be more frequent in autumn and winter (Figs. 4a,c and Figs. S3a,c of the supplemental material), with an average of $26.8 \%$ of the warm nights in winter being preceded by a heavyprecipitation event. The spatial distribution of this extreme follows the same pattern as the simultaneous extreme events, with higher frequencies along the east and southwest coasts. During spring and summer, 
a) Pr75 before Tn90 - DJF

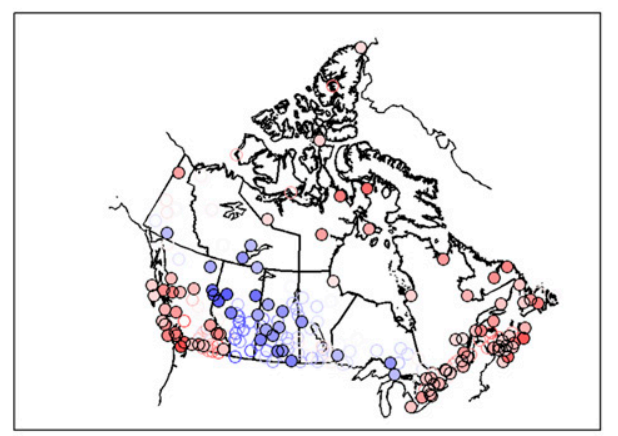

b) Pr75 before Tx90 - DJF

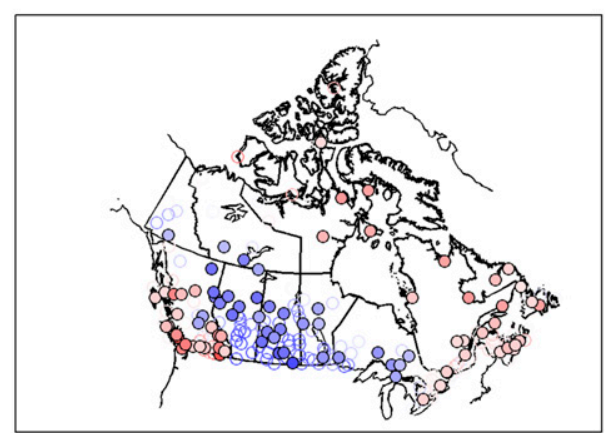

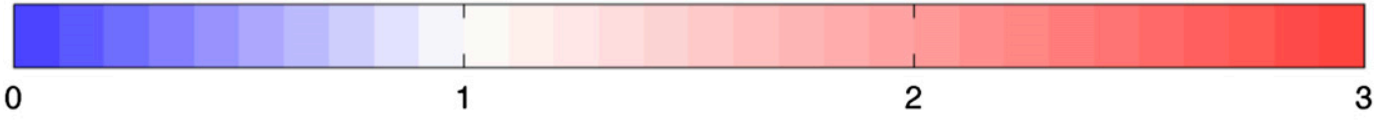

c) Pr75 before Tn90 - JJA

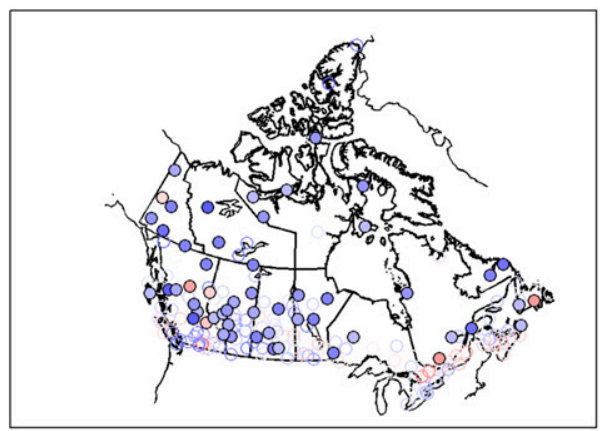

d) Pr75 before Tx90 - JJA

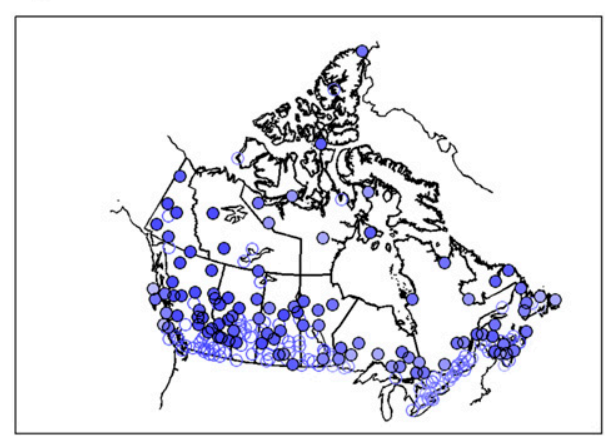

FIG. 4. Percentage of heavy-precipitation events occurring on the day before (left) a warm night and (right) a warm day for (a),(b) winter and (c),(d) summer, expressed as a ratio over the expected value (see text for more detail). Filled symbols indicate a significant relationship at the $5 \%$ level.

however, the lagged relationship is somewhat opposite to the simultaneous occurrence, with almost all stations showing a weak negative relationship.

Warm days, cold days, and cold nights preceded by a heavy-precipitation event show the same spatial distribution as the corresponding simultaneous compound extreme, although the frequencies of occurrence are lower, except for warm days in summer (see Figs. 4b,d and S3b, d for warm days and Fig. 5 and Fig. S4 of the supplemental material for cold extremes).

When lagged in the opposite direction to analyze heavyprecipitation events following a temperature extreme event, the spatial pattern of the lagged joint extremes that results is similar to the simultaneous relationship, although it is significant at a smaller number of stations (Figs. S5-S8 in the supplemental material).

\section{b. Simulated individual extreme events}

Before analyzing the joint occurrence of temperature and precipitation extreme events as simulated by RCMs, it is important to verify how well the models simulate the individual extreme events used to define the joint extremes. The spatial variability of the 75th percentile of daily precipitation (Pr75) is captured well by all models in winter, as depicted by the Taylor diagrams (Taylor 2001) shown in Fig. 6a, although most of them fail to simulate the higher values of Pr75 along the east coast. During summer most models tend to underestimate the observed spatial range of this statistic (Fig. 6b), in agreement with the biases shown for mean seasonal precipitation (Mearns et al. 2012), especially in central Canada, where Pr75 is highly underestimated. Overall, the ensemble of all of the models outperforms most of the individual models, providing the best estimate of the simulated thresholds for defining heavy-precipitation events.

Temperature-extreme thresholds show a greater spread among the models, but they seem to be better represented by models than precipitation is, both in terms of spatial variability and phasing, since the correlation between observed and simulated temperature percentiles is higher and the root-mean-square error is lower (Figs. 6c,d). Similar 
a) Pr75 before Tn10 - DJF

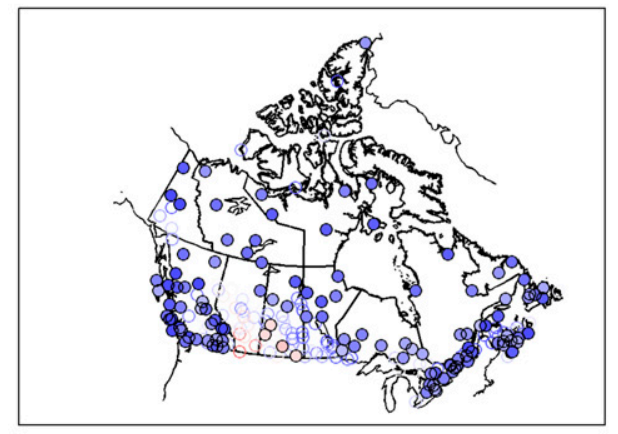

b) Pr75 before Tx10 - DJF

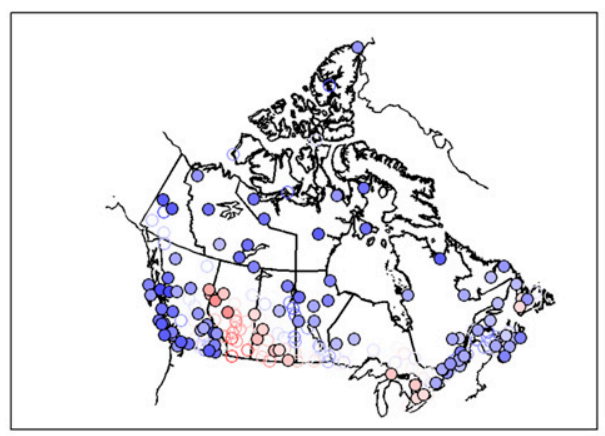

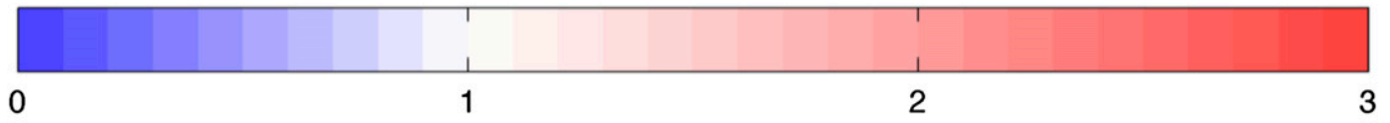

c) Pr75 before Tn10 - JJA

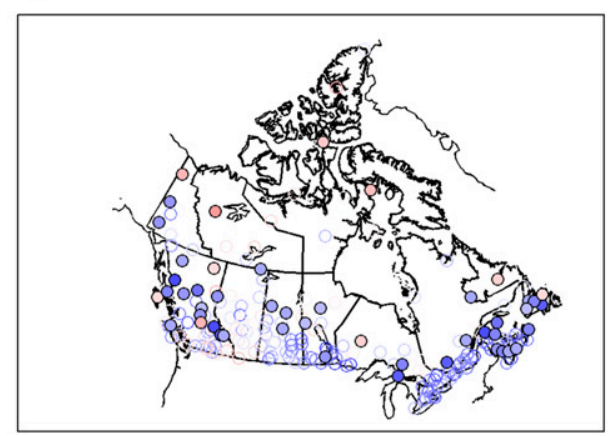

d) Pr75 before Tx10 - JJA

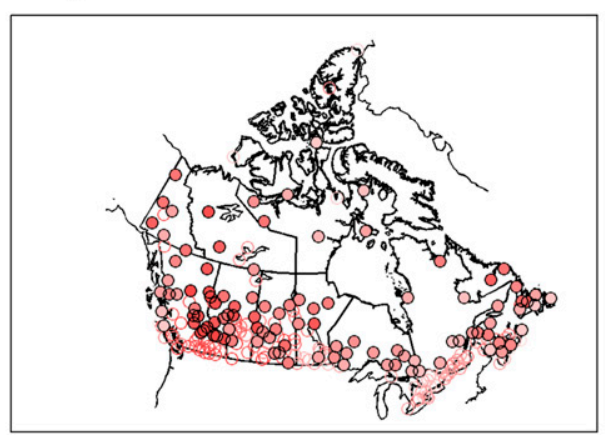

FIG. 5. As in Fig. 4, but for (a),(c) cold nights and (b),(d) cold days.

results were found for the remaining thresholds used in this study (not shown). In particular, RCM3 driven by GFDL shows the greatest underestimation of the spatial variability of Tn90 (minimum temperature above the 90th percentile) and Tx10 (maximum temperature below the 10th percentile) during most parts of the year and shows the lowest correlation with observations. On the other hand, WRFG driven by CCSM shows greater overestimations of spatial variability in most of the cases. The ensemble of all of the simulations tends to balance these differences among the individual runs, giving the best results both in terms of spatial variability and phasing, since it shows the most similar standard deviation when compared with observations and shows the highest correlations.

\section{c. Simulated joint extreme events}

Even though individual model simulations do not always accurately represent simple extreme events, the seasonal and spatial distributions of the joint extremes are captured well by the models, especially when an ensemble of several runs is used. Figure 7 shows the joint occurrence of heavy-precipitation events and warm extremes in winter (Figs. 7a,b) and cold extremes in summer (Figs. $7 \mathrm{c}, \mathrm{d})$ simulated by the ensemble of three RCMs using boundary conditions from the NCEP reanalysis. The spatial distribution of the joint extremes is captured well by the models, showing a positive significant relationship along the coasts for warm extremes in winter and negative nonsignificant relationships to the east of the Rocky Mountains. The models tend to overestimate the positive relationship of warm extremes occurring in combination with heavy-precipitation events throughout the region, however, simulating an average of $31.3 \%(25.2 \%-38.9 \%$, if the intermodel spread is considered) of warm nights and $35.9 \%(32.4 \%-44.4 \%)$ of warm days in winter (Figs. $7 a, b)$ also experiencing heavy-precipitation events over the whole country, as compared with the $25.6 \%(25.2 \%-$ $26.9 \%$, if a $90 \%$ confidence interval is considered) and $30.5 \%(29.8 \%-32.2 \%)$ frequencies that are respectively observed. In British Columbia, Canada, which is one of the provinces with the highest observed frequency of occurrence of this joint extreme, an average of $41.2 \%$ $(38.7 \%-46.2 \%)$ of the warm nights in winter are expected to experience heavy-precipitation events according to the 
a) Pr75 - DJF

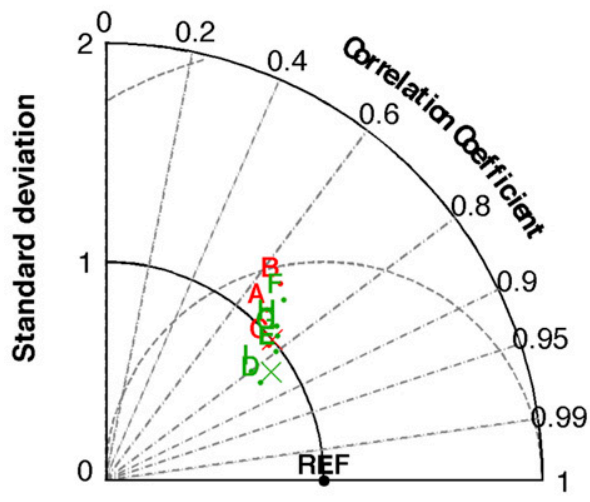

REF - Stations 1980-2004

A - HRM3-NCEP

B - RCM3-NCEP

c) Tn90 - DJF

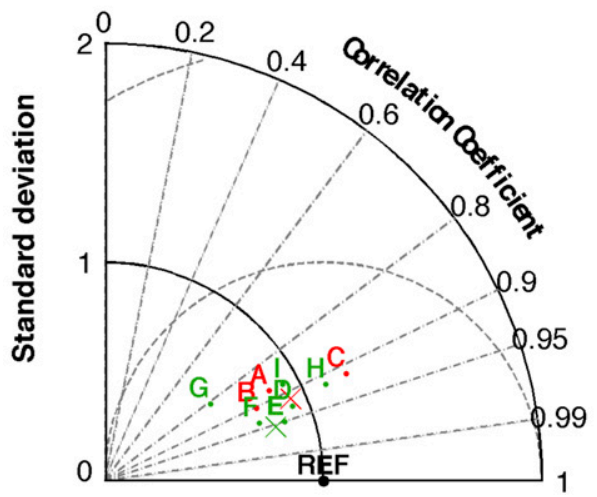

b) Pr75 - JJA

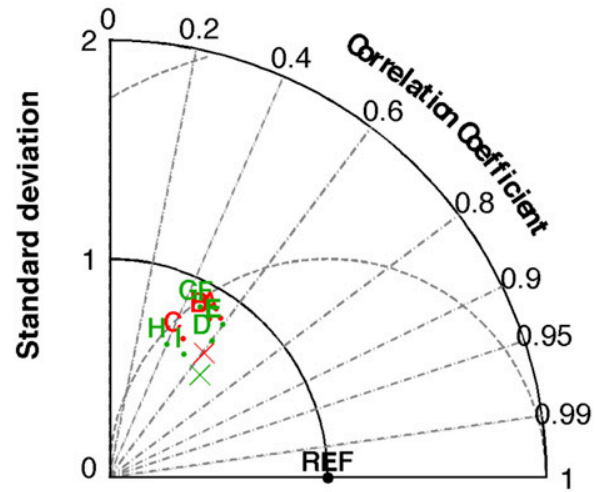

E - HRM3-HadCM3
F- RCM3-CGCM3
G - RCM3-GFDL

H - WRFG-CCSM

I - WRFG-CGCM3

$X$ - ENS-GCM

FIG. 6. Spatial Taylor diagrams of the 75th percentile of precipitation in (a) winter and (b) summer, (c) the 90th percentile of minimum temperature in winter, and (d) the 10th percentile of maximum temperature in summer, comparing model simulations with observations. Standard deviations and root-mean-square differences are normalized by the reference standard deviation.

ensemble of simulations, whereas only $25.7 \%(23.9 \%-$ $26.9 \%$ ) were observed during the period 1980-2004. If the intermodel spread is considered, however, these differences are not significant. The seasonality of the distribution of joint extremes is also captured well by the models that are able to reproduce the negative relationship between warm days and heavy precipitation during summer (see supplemental Fig. S10c).

Joint extremes associated with cold events are also well captured by the models. The simulated relationship between heavy-precipitation events and cold nights was negative for all year and was negative (positive) during winter (summer) for cold days (Figs. 7c,d and Figs. S11 and S12 in the supplemental material). The percentage of cold days occurring simultaneously with heavy-precipitation events is slightly underestimated by the models for regions of enhanced occurrence of this joint extreme event: $27.7 \%$ ( $26.5 \%-31.4 \%$, if the intermodel spread is considered) as compared with the $30.6 \%(29.7 \%-31.0 \%)$ observed in summer, and $37.0 \%(30.6 \%-43.9 \%)$ as compared with $40.3 \%(38.8 \%-40.9 \%)$ observed in British Columbia. Again, these differences are not significant when the intermodel spread is considered.

When boundary conditions are given by GCMs instead of reanalysis, similar patterns of temporal and spatial variability of joint extremes are found (Fig. 8), although the area of significance and the intermodel spread are found to be larger. The six-member ensemble of RCMs shows that heavy-precipitation events combined with warm extremes occur significantly more often along the coasts during autumn and winter, with an average over the whole country of $30.1 \%(16.1 \%-41.5 \%)$ for warm nights and $33.4 \%(17.8 \%-47.5 \%)$ for warm days during winter. Cold days are more frequently associated with heavyprecipitation events in summer, with a spatial average of $23.8 \%(15.5 \%-31.4 \%)$, and cold nights are very rarely 
a) Pr75 \& Tn90 - DJF

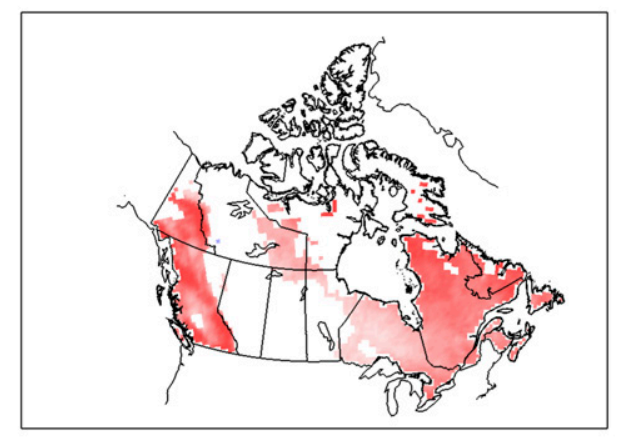

b) Pr75 \& Tx90 - DJF

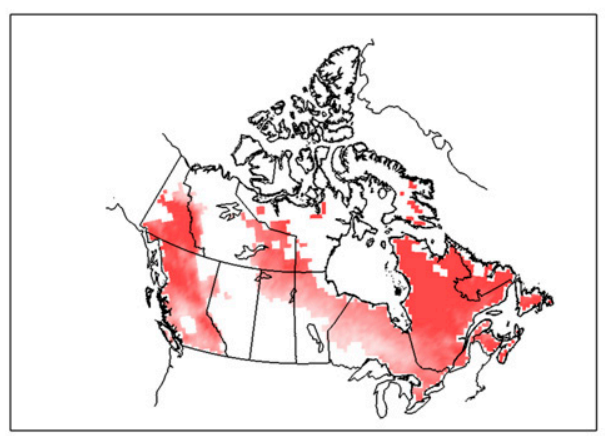

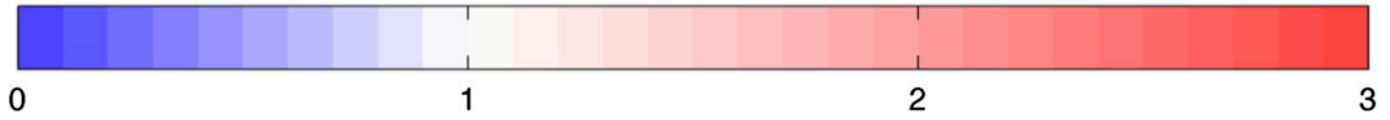

c) Pr75 \& Tn10 - JJA

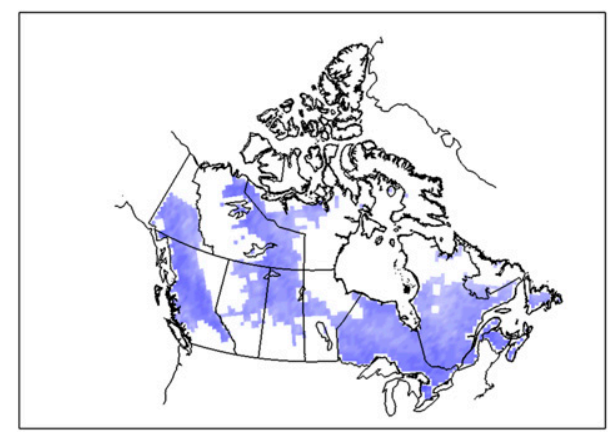

d) Pr75 \& Tx10 - JJA

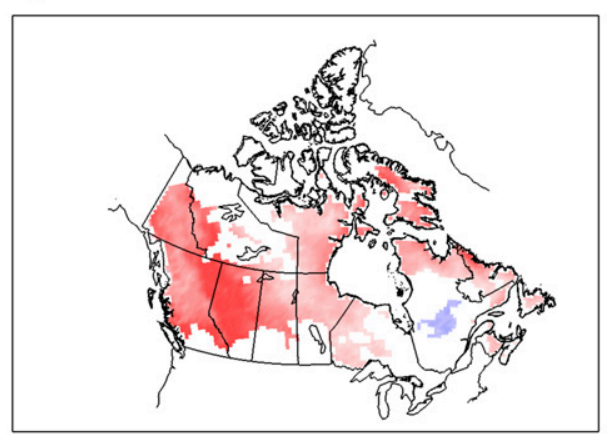

FIG. 7. Percentages of (a) warm nights and (b) warm days in winter and (c) cold nights and (d) cold days in summer occurring simultaneously with heavy-precipitation events, expressed as a ratio over the expected value, as simulated by the three-member ensemble of the RCMs driven by the NCEP reanalysis. Only grid points with a significant relationship at the $5 \%$ level are shown.

found to be concurrent with intense precipitation (less than $10 \%$ of the time).

The spatial Taylor diagrams shown in Fig. 9 provide a summary of the model performance in simulating the joint extreme distribution. It can be seen that all models captured very well the spatial range of frequencies of extreme-temperature events combined with heavy precipitation since all models have a standard deviation very similar to the observed. There are two models that tend to underestimate this statistic for all types of extremes and seasons: the HRM3 with GFDL boundary conditions and the WRFG when driven by CCSM. The correlation between model simulations and observations is usually low, indicating that the models do not locate the occurrence of maximum and minimum frequencies accurately. This result could in part be due to the fact that there are a few isolated stations along Hudson Bay and northern Québec that show a high frequency of occurrence of joint extreme events, especially for warm extremes, whereas models do not capture a stronger signal in that region. However, as seen from Figs. 7 and 8, the spatial distribution of the occurrence of joint extremes is captured well by most of the RCMs from the NARCCAP project. As a result of compensation among models, the ensemble of all simulations usually outperforms individual models.

The analysis of the simulated lagged joint extremes shows results that are similar to what was observed at stations, with lower frequencies of occurrence of heavy precipitation and extreme temperatures for all combinations of extremes and all seasons of the year, especially when heavy precipitation follows an extreme-temperature event (not shown).

\section{Summary and conclusions}

In this study, we addressed the question of whether there is a significant relationship between the occurrence of heavy precipitation and extreme-temperature 
a) Pr75 \& Tn90 - DJF

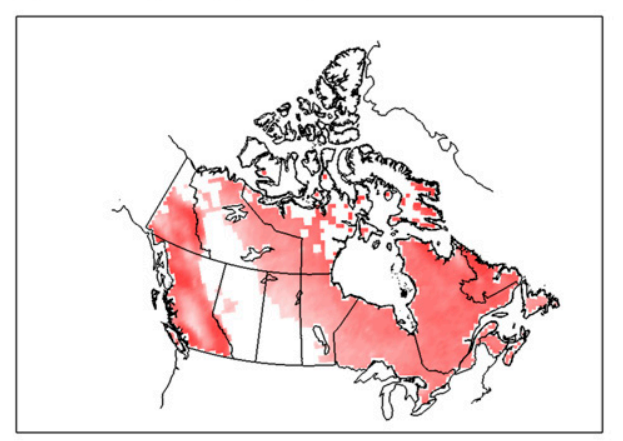

b) Pr75 \& Tx90 - DJF

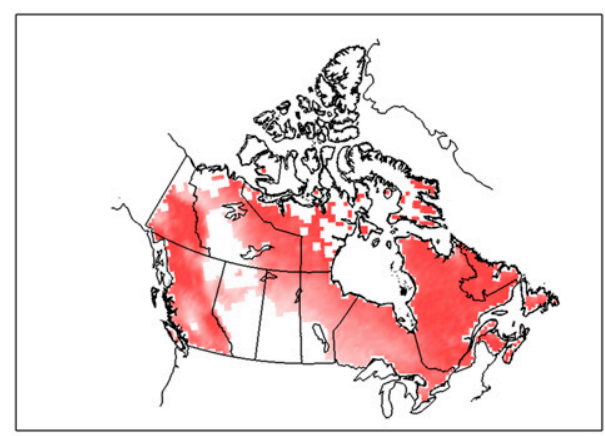

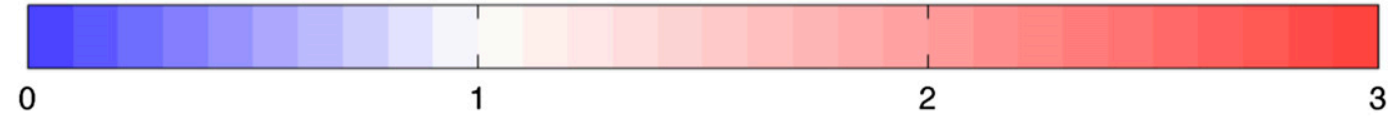

c) Pr75 \& Tn10 - JJA

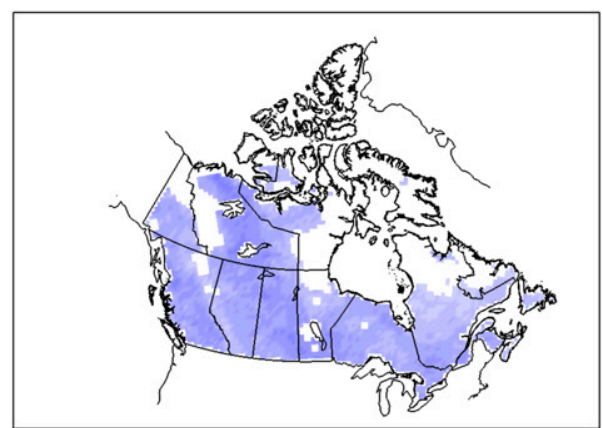

d) Pr75 \& Tx10 - JJA

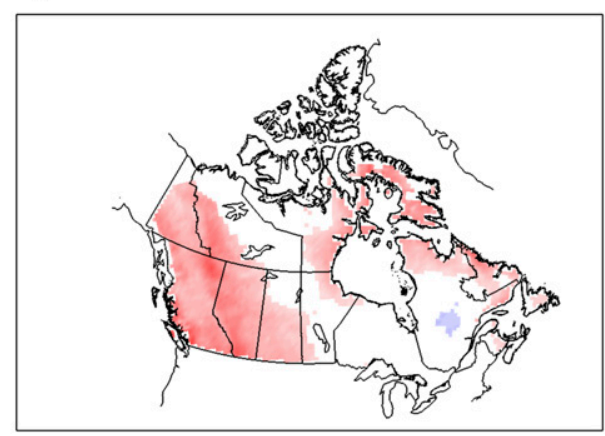

FIG. 8. As in Fig. 7, but for the six-member ensemble of the RCMs driven by GCMs.

events in Canada with a simple statistical approach. From daily series of minimum and maximum temperature and daily precipitation observed at 293 stations across the country, the simultaneous and lagged joint distributions of temperature and precipitation extremes were analyzed for the common period 1980-2004.

Results showed that a significant relationship between heavy precipitation and extreme-temperature events exists over Canada, with the strength and sign of this relationship varying through the year for the different types of joint extreme events. The simultaneous occurrence of heavy-precipitation events and warm nights was shown to be positive, significant at more than one-half of the stations, with an average of more than one of every four warm nights experiencing intense precipitation. The spatial distribution of this joint extreme event showed that the east and southwest coasts are the most prominent regions to have an enhanced probability of occurrence of intense precipitation during warm nights, while a negative relationship was found in Alberta and Saskatchewan, although it was significant at less than $10 \%$ of the stations in the region. In agreement with previous studies on the relationship between precipitation and temperature that were based on mean values, warm and wet conditions are more likely to occur during autumn and winter across the country. In a similar way, heavy-precipitation events and warm days also showed a significant positive relationship during winter in eastern and southwestern Canada, whereas a negative relationship was found during summer at almost every station in Canada. Cold days show the opposite pattern, with a positive association with intense rainfall in summer and a negative association during winter. Cold nights and heavy-precipitation events showed a significant negative correlation throughout the year, indicating that these types of events do not tend to occur simultaneously.

The occurrence of heavy precipitation on the day before a temperature extreme event showed a seasonality and spatial distribution that are similar to the simultaneous occurrence of most of the joint extremes analyzed in this study, although a weaker and less significant signal was obtained. This result suggests that intense precipitation can lead to an anomalous drop in maximum temperature during summer that is due to a cooling of the 
a) Pr75 \& Tn90 - DJF

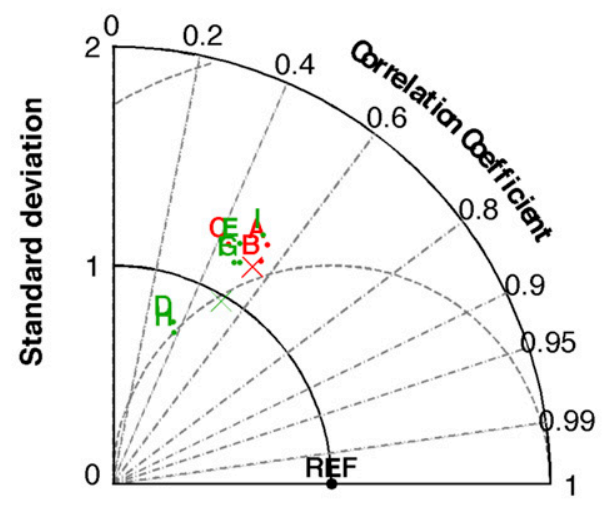

REF - Stations 1980-2004

A - HRM3-NCEP

B - RCM3-NCEP

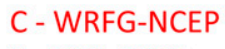

$X$ - ENS-NCEP

D - HRM3-GFDL

c) Pr75 \& Tn10 - JJA

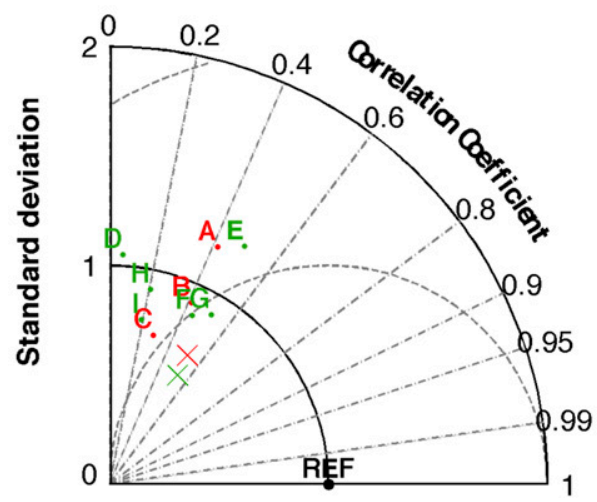

b) Pr75 \& Tx90 - DJF
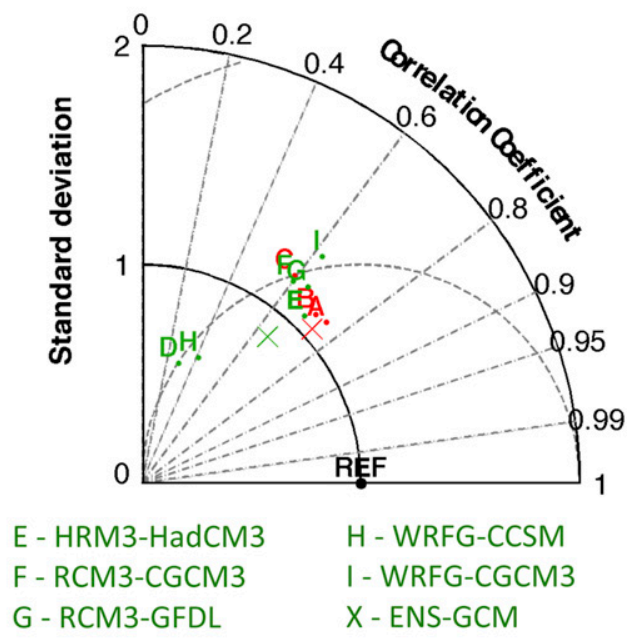

d) Pr75 \& Tx10 - JJA

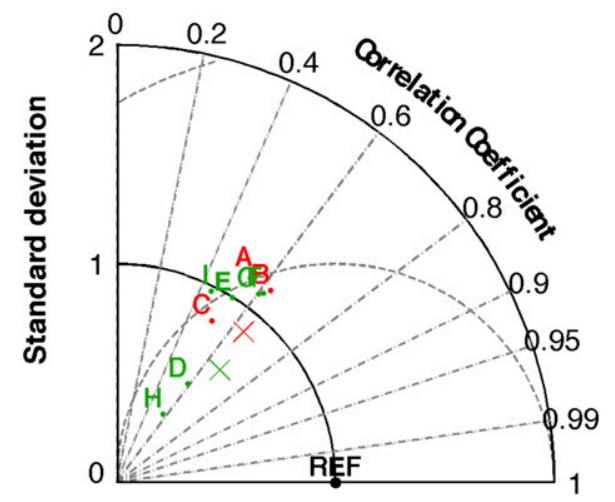

FIG. 9. Spatial Taylor diagrams of the combined extreme events of heavy-precipitation events and (a) warm nights and (b) warm days in winter and (c) cold nights and (d) cold days in summer, comparing model simulations with observations. Standard deviations and root-mean-square differences are normalized by the reference standard deviation.

surface since part of the heat is used to evaporate the excess water or a rise in minimum temperature during winter because of increased cloudiness during nighttime hours. When lagged in the opposite direction, a weak signal was obtained for all joint extremes, indicating that the occurrence of intense rainfall is not dependent on the occurrence of extremely cold or warm conditions on the previous day.

The same analysis was performed with historical runs of the climate simulated by RCMs from the NARCCAP project. Even though individual models do not always accurately represent simple extreme events, the seasonal and spatial distributions of the joint extremes are captured well by the models, especially when an ensemble of several runs is used, providing a useful tool with which to analyze the joint occurrence of heavy precipitation and extreme-temperature events.
Further research is required to explore the basis of the relationships found in this study between the occurrence of intense rainfall and extreme-temperature events. Soil moisture feedbacks can be a major forcing of the occurrence of heat waves, as was the case for the 2003 central European heat wave that was preceded by a precipitation deficit during at least four months (Fischer et al. 2007). In a more general case, Vautard et al. (2007) found that 9 of the 10 hottest summers in the period from 1948 to 2005 had a negative anomaly of rainfall frequency over southern Europe, which is consistent with the negative relationship between intense-rainfall frequency and warm days found in this study. According to Fischer et al. (2007), drought conditions may induce changes in the atmospheric circulation and advection of air masses that can lead to changes in regions outside the area affected by the precipitation deficit. Therefore, a global-scale analysis is required to 
understand the physical mechanisms that can give place to wet and warm/cold conditions across Canada, which is beyond the scope of this study.

Acknowledgments. This study was funded by NSERC CRD, CREATE, and the Discovery Grant program. The authors thank Lucie Vincent and Éva Mekis for providing the observed data and Ed Wiebe for technical support. Special thanks are given to Dr. Matilde Rusticucci. We also thank the North American Regional Climate Change Assessment Program for providing the data used in this paper. NARCCAP is funded by the National Science Foundation, the U.S. Department of Energy, the National Oceanic and Atmospheric Administration, and the U.S. Environmental Protection Agency Office of Research and Development.

\section{REFERENCES}

Bustinza, R., G. Lebel, P. Gosselin, D. Bélanger, and F. Chebana, 2013: Health impacts of the July 2010 heat wave in Québec, Canada. BMC Public Health, 13, 56, doi:10.1186/ 1471-2458-13-56.

Collins, W. D., and Coauthors, 2006: The Community Climate System Model version 3 (CCSM3). J. Climate, 19, 2122-2143, doi:10.1175/JCLI3761.1.

Ding, T., and W. Qian, 2011: Geographical patterns and temporal variations of regional dry and wet heatwave events in China during 1960-2008. Adv. Atmos. Sci., 28, 322-337, doi:10.1007/ s00376-010-9236-7.

Donat, M. G., and Coauthors, 2013: Updated analyses of temperature and precipitation extreme indices since the beginning of the twentieth century: The HadEX2 dataset. J. Geophys. Res. Atmos., 118, 2098-2118, doi:10.1002/jgrd.50150.

Fischer, E. M., S. I. Seneviratne, D. Lüthi, and C. Schär, 2007: Contribution of land-atmosphere coupling to recent European summer heat waves. Geophys. Res. Lett., 34, L06707, doi:10.1029/2006GL029068.

Flato, G. M., G. J. Boer, W. G. Lee, N. A. McFarlane, D. Ramsden, M. C. Reader, and A. J. Weaver, 2000: The Canadian Centre for Climate Modeling and Analysis Global Coupled Model and its climate. Climate Dyn., 16, 451-467, doi:10.1007/ s003820050339.

Geng, Q., R. Mo, M. Brugman, B. Snyder, J. Goosen, and G. Pearce, 2012: Interaction of an intense Pacific low pressure system with a strong Arctic outbreak over British Columbia: Forecast challenges of the early December 2007 storm. Atmos.-Ocean, 50, 95108, doi:10.1080/07055900.2012.656261.

GFDL Global Atmospheric Model Development Team, 2004: The new GFDL global atmospheric and land model AM2-LM2: Evaluation with prescribed SST simulations. J. Climate, 17, 4641-4673, doi:10.1175/JCLI-3223.1.

Giorgi, F., M. R. Marinucci, and G. T. Bates, 1993a: Development of a second-generation regional climate model (RegCM2). Part I: Boundary-layer and radiative transfer processes. Mon. Wea. Rev., 121, 2794-2813, doi:10.1175/1520-0493(1993)121<2794: DOASGR $>2.0 . \mathrm{CO} ; 2$.

$\longrightarrow,-$ - G. de Canio, and G. T. Bates, 1993b: Development of a second-generation regional climate model (RegCM2). Part
II: Convective processes and assimilation of lateral boundary conditions. Mon. Wea. Rev., 121, 2814-2832, doi:10.1175/ 1520-0493(1993)121<2814:DOASGR > 2.0.CO;2.

Gordon, C., C. Cooper, C. A. Senior, H. Banks, J. M. Gregory, T. C. Johns, J. F. B. Mitchell, and R. A. Wood, 2000: The simulation of SST, sea ice extents and ocean heat transports in a version of the Hadley Centre coupled model without flux adjustments. Climate Dyn., 16, 147-168, doi:10.1007/s003820050010.

Isaac, G. A., and R. A. Stuart, 1992: Temperature-precipitation relationships for Canadian stations. J. Climate, 5, 822-830, doi:10.1175/1520-0442(1992)005<0822:TRFCS $>2.0$.CO;2.

Jakob, M., and M. Church, 2011: The trouble with floods. Can. Water Resour. J., 36, 287-292, doi:10.4296/cwrj3604928.

Jiang, Y., and B. Huang, 2000: Effects of drought or heat stress alone and in combination on Kentucky bluegrass. Crop Sci., 40, 1358-1362, doi:10.2135/cropsci2000.4051358x.

Jones, R., D. Hassell, D. Hudson, S. Wilson, G. Jenkins, and J. Mitchell, 2003: Generating high resolution climate change scenarios using PRECIS. UNDP National Communications Unit Workbook, $34 \mathrm{pp}$.

Kanamitsu, M., W. Ebisuzaki, J. Woollen, S.-K. Yang, J. J. Hnilo, M. Fiorino, and G. L. Potter, 2002: NCEP-DOE AMIP-II Reanalysis (R-2). Bull. Amer. Meteor. Soc., 83, 1631-1643, doi:10.1175/BAMS-83-11-1631.

Kysely, J., L. Pokorna, J. Kyncl, and B. Kriz, 2009: Excess cardiovascular mortality associated with cold spells in the Czech Republic. BMC Public Health, 9, 19, doi:10.1186/1471-2458-9-19.

Lau, W. K. M., and K.-M. Kim, 2012: The 2010 Pakistan flood and Russian heat wave: Teleconnection of hydrometeorological extremes. J. Hydrometeor., 13, 392-403, doi:10.1175/ JHM-D-11-016.1.

Levinson, D. H., and A. M. Waple, 2004: State of the climate in 2003. Bull. Amer. Meteor. Soc., 85, 881-881, doi:10.1175/ BAMS-85-6-Levinson.

Ma, W., C. Yang, C. Chu, T. Li, J. Tan, and H. Kan, 2013: The impact of the 2008 cold spell on mortality in Shanghai, China. Int. J. Biometeor., 57, 179-184, doi:10.1007/s00484-012-0545-7.

Madden, R. A., and J. Williams, 1978: The correlation between temperature and precipitation in the United States and Europe. Mon. Wea. Rev., 106, 142-147, doi:10.1175/1520-0493(1978)106<0142: TCBTAP $>2.0 . \mathrm{CO} ; 2$.

Matsueda, M., 2011: Predictability of Euro-Russian blocking in summer of 2010. Geophys. Res. Lett., 38, L06801, doi:10.1029/ 2010 GL046557.

McGregor, G. R., C. A. T. Ferro, and D. B. Stephenson, 2005: Projected changes in extreme weather and climate events in Europe. Extreme Weather Events and Public Health, W. Kirch, B. Menne, and R. Bertollini, Eds., Springer, 13-24.

Mearns, L. O., and Coauthors, 2012: The North American Regional Climate Change Assessment Program: Overview of Phase I results. Bull. Amer. Meteor. Soc., 93, 1337-1362, doi:10.1175/ BAMS-D-11-00223.1.

Mekis, É., and L. A. Vincent, 2011: An overview of the Second Generation Adjusted Daily Precipitation Dataset for Trend Analysis in Canada. Atmos.-Ocean, 49, 163-177, doi:10.1080/ 07055900.2011 .583910$.

Pal, J. S., E. E. Small, and E. A. B. Eltahir, 2000: Simulation of regional-scale water and energy budgets: Representation of subgrid cloud and precipitation processes within RegCM. J. Geophys. Res., 105, 29 579-29 594, doi:10.1029/ 2000JD900415.

- , and Coauthors, 2007: Regional climate modeling for the developing world: The ICTP RegCM3 and RegCNET. 
Bull. Amer. Meteor. Soc., 88, 1395-1409, doi:10.1175/ BAMS-88-9-1395.

Pope, V. D., M. L. Gallani, P. R. Rowntree, and R. A. Stratton, 2000: The impact of new physical parameterizations in the Hadley Centre climate model: HadAM3. Climate Dyn., 16, 123-146, doi:10.1007/s003820050009.

Schär, C., and G. Jendritzky, 2004: Hot news from summer 2003. Nature, 432, 559-560, doi:10.1038/432559a.

Scinocca, J. F., and N. A. McFarlane, 2004: The variability of modeled tropical precipitation. J. Atmos. Sci., 61, 1993-2015, doi:10.1175/1520-0469(2004)061<1993:TVOMTP>2.0.CO;2.

Shabbar, A., and B. Bonsal, 2003: An assessment of changes in winter cold and warm spells over Canada. Nat. Hazards, 29, 173-188, doi:10.1023/A:1023639209987.

Simonovic, S. P., 2009: Managing flood risk, reliability and vulnerability. J. Flood Risk Manage., 2, 230-231, doi:10.1111/ j.1753-318X.2009.01040.x.

Skamarock, W. C., J. B. Klemp, J. Dudhia, D. O. Gill, D. M. Barker, W. Wang, and J. G. Powers, 2005: A description of the Advanced Research WRF version 2. NCAR Tech. Note NCAR/TN-468+STR, 88 pp. [Available online at http:// www2.mmm.ucar.edu/wrf/users/docs/arw_v2.pdf.]

Stocker, T. F., and Coauthors, 2013: Climate Change 2013: The Physical Science Basis. Cambridge University Press, 1535 pp. [Available online at http://www.climatechange2013.org/images/ report/WG1AR5_ALL_FINAL.pdf.]

Taylor, K. E., 2001: Summarizing multiple aspects of model performance in a single diagram. J. Geophys. Res., 106, 71837192, doi:10.1029/2000JD900719.

Trenberth, K. E., 1999: Conceptual framework for changes of extremes of the hydrological cycle with climate change. Climatic Change, 42, 327-339, doi:10.1023/A:1005488920935.
- and D. J. Shea, 2005: Relationships between precipitation and surface temperature. Geophys. Res. Lett., 32, L14703, doi:10.1029/2005GL022760.

_ , and J. T. Fasullo, 2012: Climate extremes and climate change: The Russian heat wave and other climate extremes of 2010. J. Geophys. Res., 117, D17103, doi:10.1029/2012JD018020.

Vautard, R., and Coauthors, 2007: Summertime European heat and drought waves induced by wintertime Mediterranean rainfall deficit. Geophys. Res. Lett., 34, L07711, doi:10.1029/ 2006 GL028001.

Vincent, L. A., X. L. Wang, E. J. Milewska, H. Wan, F. Yang, and V. Swail, 2012: A second generation of homogenized Canadian monthly surface air temperature for climate trend analysis. J. Geophys. Res., 117, D18110, doi:10.1029/2012JD017859.

Westra, S., L. V. Alexander, and F. W. Zwiers, 2013: Global increasing trends in annual maximum daily precipitation. J. Climate, 26, 3904-3918, doi:10.1175/JCLI-D-12-00502.1.

Wilks, D. S., 1997: Resampling hypothesis tests for autocorrelated fields. J. Climate, 10, 65-82, doi:10.1175/1520-0442(1997)010<0065: RHTFAF $>2.0 . \mathrm{CO} ; 2$.

_ 2011: Statistical Methods in the Atmospheric Sciences. Academic Press, 676 pp.

Yates, F., 1934: Contingency tables involving small numbers and the $\chi^{2}$ test. Supplement to the J. Roy. Stat. Soc., 1 (Suppl.), 217235. [Available online at http://www.jstor.org/stable/2983604.]

_ 1984: Tests of significance for $2 \times 2$ contingency tables. J. Roy. Stat. Soc., 147A, 426-463, doi:10.2307/2981577.

Zhang, X., L. V. Alexander, G. C. Hegerl, P. Jones, A. M. G. Klein Tank, T. C. Peterson, B. Trewin, and F. W. Zwiers, 2011: Indices for monitoring changes in extremes based on daily temperature and precipitation data. Wiley Interdiscip. Rev.: Climate Change, 2, 851-870, doi:10.1002/wcc.147. 